\title{
Factors responsible for the effective introduction of water-saving irrigation facilities in the Tarim River Basin
}

\author{
T. Yamamoto ${ }^{1}$, A. Jalaldin ${ }^{2} \&$ T. Nagasawa ${ }^{1}$ \\ ${ }^{I}$ Research Faculty of Agriculture, Hokkaido University, Japan \\ ${ }^{2}$ College of Resources and Environmental Sciences, \\ Xinjiang University, China
}

\begin{abstract}
Chronic water shortage is one of the most pressing problems in the arid areas of China and as a compensation measure, the introduction of water-saving irrigation facilities has been proposed for water use in agriculture. However, in the Ugen River Basin, these water-saving irrigation facilities have produced varying results ranging from success to failure. Therefore, this study examines such cases and considers the factors responsible for the effective introduction of watersaving irrigation facilities in these regions. In general, capitalist farmers are individually responsible for the introduction, maintenance and management of the water-saving facilities, whereas general farmers collectively manage and maintain the facilities built with government subsidies. In addition, this study reports two cases in which collective management either required initial investments or covered all of the initial investment costs through government subsidies. However, these facilities were not necessarily well managed because of the differences in the management group, thus affecting their outcomes as an effective water-saving irrigation facility. By using game theory to obtain an optimal solution, the results of this paper indicate that the cost of work and maintenance accrued by the introduction of the water-saving facilities was less compared to both the incentives received in water-fee reductions as well as the increased yield of water-saving irrigation. Finally, we suggest that either the current yield needs to be increased twofold or the water fee needs to be increased for effective management of water-saving irrigation facilities, particularly in regard to collective management.
\end{abstract}

Keywords: arid area, game theory, agricultural water use. 


\section{Introduction}

In arid regions of China, agricultural production requires a significant amount of water provided by an irrigation system. However, chronic water shortage is one of the most pressing problems in these arid regions, which is mostly due to industrial development and lifestyle changes as well as advancements in irrigation and agriculture. Agricultural water use tends to be restrained since it uses a high percentage of the total water demand. For example, recently in the Xinjiang Uygur Autonomous Region, the government promoted the active use of groundwater since the ratio of groundwater use was lower compared to other areas in China. Since this situation was the same in the Tarim River Basin, water-saving irrigation has been introduced in this area as well.

However, in the Ugen River Basin, which is the branch of the Tarim River located in the northern part of the Taklamakan Desert, cases of water-saving irrigation facilities have included varying results ranging from success to failure. In this case, the differences of management for the water-saving irrigation facilities are noted, which include two overall types of farmers. First, the capitalist farmers who are individually responsible for the introduction, maintenance and management of the facility. Second, the general farmers who collectively manage and maintain the facilities built with government subsidies. In addition, two cases of collective management required either initial investments or covered all of the initial investment costs through government subsidies. These facilities were not necessarily well managed because of the differences in the management group, thus affecting their outcomes as an effective water-saving irrigation facility [1].

Based on the above cases, this study examines the effect of water-saving irrigation and considers the factors responsible for their effective introduction. In addition, by using game theory to obtain optimal solution, this paper investigates the cost of work and maintenance accrued by the introduction of the watersaving facilities and compares it to both the incentives received in water-fee reductions as well as the increased yield of water-saving irrigation.

\section{Methods and outline of survey area}

This investigation targeted Xayar County located on the northern edge of the Taklamakan Desert in the Xinjiang Uygur Autonomous Region. More specifically, Xayar County is located downstream on the Ugen River, which is the branch of the Tarim River (Fig. 1). As of 2011, the cultivated area in the Ugen River irrigation district covered a total of 76,000 hectares in which cotton is the primary crop. In addition, the irrigation water depends upon the Kyzyl Dam located upstream. The administrative organization of the county consists of eight 'townships and towns': Honqi, Yingmaili, Nuerbake, Hailou, Xayar, Xinkennongjiao, Gulibake and Tuoybao [1].

The irrigation water for these townships and towns is primarily from the Ugen River and there are many farmers in this particular irrigation district. In addition, the average lining rate of the total canal length is only $4 \%$ with a conveyance 
efficiency of approximately $60 \%$ and an irrigation efficiency of only $40 \%$ [2]. On the other hand, the farmland is developed by national enterprises located in Xinkennongjiao and there are many capitalist farmers compared to the relatively few general farmers [2].

To grasp the situation of agricultural water use and the management of watersaving irrigation and agricultural production, interviews with representatives of the branch offices of the agency as well as the farmers were conducted from 2003 to 2011. In addition, measurements were made of the groundwater tables in the fields and wells of this particular area. We considered the efficiency of watersaving irrigation based on both interviews as well as field research and discussed the problem for the introduction of water-saving irrigation by using game theory. In this case, discharge data was supported by a group analysis from Xinjiang University.

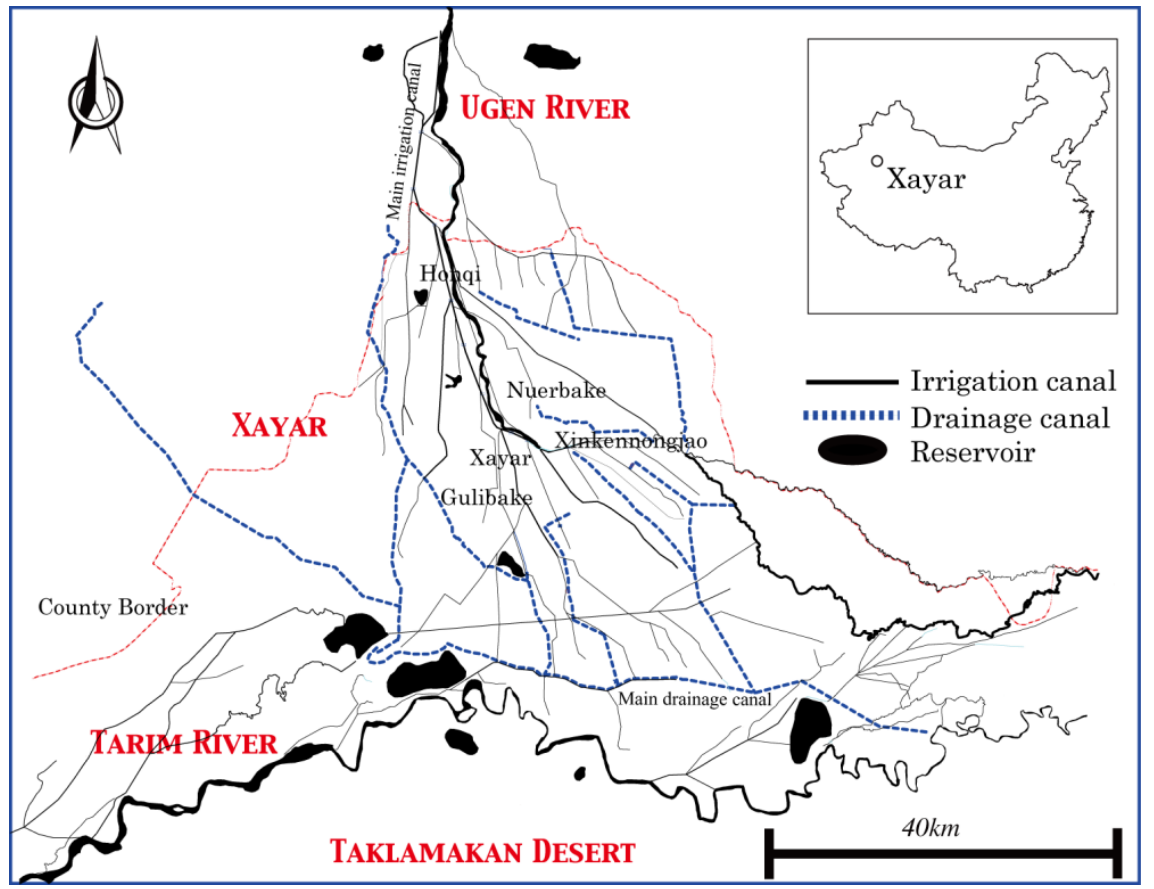

Figure 1: $\quad$ Outline of the survey area.

\section{Effects after the introduction of water-saving irrigation}

\subsection{Initial conditions for water-saving irrigation}

Since 2007, a water-saving project has been in place for farmers in Xayar County. Water-saving irrigation facilities (i.e. drip irrigation) have been improved for approximately 12,000 hectares of farmland, which is equal to about $20 \%$ of the total cultivated area in the county. In addition, the Chinese 
government subsidized one-third of the total cost of construction, although this subsidiary cost varies according to the annual budget and financial situation of the target district. However, the remaining cost is borne by both the county and the farmers and, in this case, farmers paid approximately $800 \mathrm{CNY}$ per 0.067 hectare.

Furthermore, irrigation facilities cannot necessarily be constructed on just any farmland since local construction standards recommend one irrigation facility for approximately 14-27 hectares. Construction of such facilities can be difficult for the common family farmer since each farmer in this region manages around 1.32.0 hectares of land. In the case of Tarim Township, this would amount to approximately 6.7 hectares, which would not be cost-efficient for one family farmer. Therefore, it is never an inexpensive investment considering that their profit from production is only about 1,200-2,000 CNY per year [2].

\subsection{Change of water supply due to the introduction of drip irrigation}

Figure 2 shows the water-supply volume for each township in March and July since 1998. Further examination shows merely a change of supply volume of
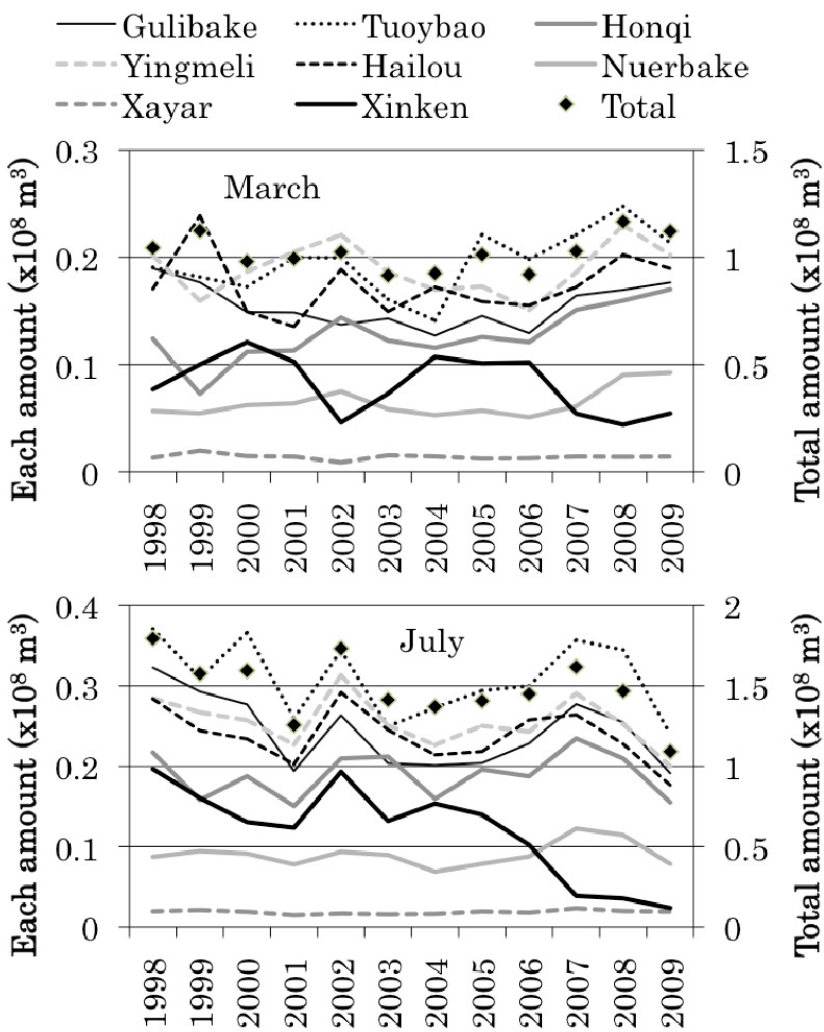

Figure 2: $\quad$ Irrigation water amount in March and July (1998-2009). 
about $10^{8} \mathrm{~m}^{3}$ in the month of March and that all of the townships increased their water supply volumes except for the town of Xinkennongjiao. In regard to the month of July, the total water-supply volume shows a decreasing trend that has occurred since 2007, which is also seen for each township on one level or another. More specifically, this trend is remarkable for Xinkennongjiao in which the factors of decreased water supply are considered as an impact of climate change or water transport from agricultural uses to other requirements.

In Xinkennongjiao, a drip-irrigation system was introduced in 2003 and the irrigated area by this system occupied more than $90 \%$ of the total irrigated area. In addition, the water-supply volume has decreased steadily since 2007 since the system decreased the intake of water from the river. On the other hand, the supply of water during the sowing period also decreased since drip irrigation is primarily used only in the summers. However, recently, some farmers have begun using ground water due to the shortage of river water.

\subsection{Yield production changes from drip irrigation}

In this particular area, the average yield of cotton is approximately 300 to $450 \mathrm{~kg}$ per 10 acres. Based on interview research, it is clear that many farmers believe that their yield production has increased because of drip irrigation. For example, in Gulibake Township, the yield increased from $300 \mathrm{~kg}$ in 2008 to $720 \mathrm{~kg}$ in 2009 per 10 acres after a drip-irrigation system was introduced in 2009. This increasing factor has a fertilising effect that has decreased soil salinization. This was seen on every farm including Xinkennongjiao. However, the yields did not necessarily increase for all of the farms in the collective management facilities. In this case, such failure was due to the lack of awareness for collective management as well as the low qualities of the materials [2].

\subsection{Change of groundwater level due to the introduction of drip irrigation}

Figure 3 shows the change in groundwater depth in drip-irrigation fields (particularly Xinkennongjiao and Gulibake Townships) and border irrigation fields (such as Nuerbake Township). In Nuerbake Township, where there are no

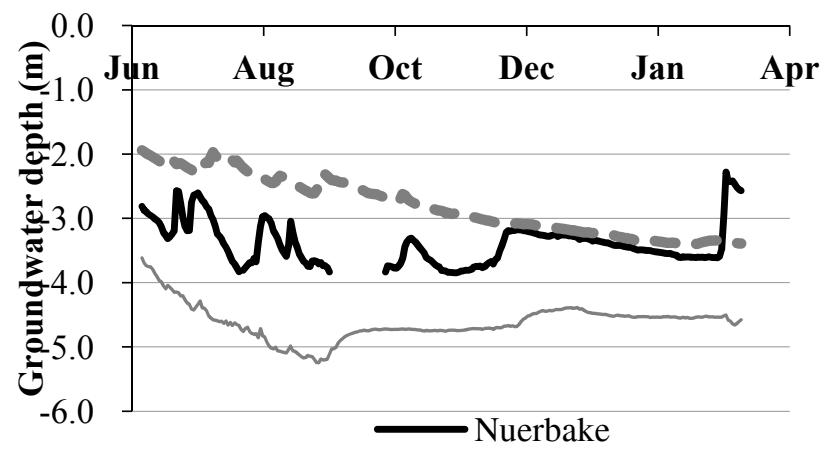

Figure 3: Changes in groundwater depth of cotton fields (2009.6-2010.3). 
fields with drip irrigation, the groundwater table increased significantly with border irrigation. However, in Gulibake Township, in which the groundwater table had been high before the installation of drip irrigation, showed a minimal increase. It appears that this low groundwater table occurred due to soil salinization.

\section{Evaluating water-saving irrigation systems using game theory}

\subsection{Application of game theory}

Here we consider the introduction of water-saving irrigation systems in collective management facilities by using game theory. In addition, prisoners' dilemma was used in this game theory for the evaluation method. Game theory is utilised for a logical analysis about strategic decision-making. The prisoner's dilemma is a canonical example in game theory that shows why two individuals might not cooperate with one another, even if it appears that it would be in their best interest to do so (Table 1).

Table 2 shows the critical rule for drip irrigation in which factors were considered based on interview research and information. In this case, Players A and $\mathrm{B}$ represent the farmers after the introduction of the collective drip-irrigation facility. The profit and loss indices include X1: initial cost, X2: maintenance cost, X3: time and maintenance works, X4: reduction of water fee and X5: increasing production for each of the farmers.

Table 1: $\quad$ Concept of prisoner's dilemma [3].

\begin{tabular}{|c|c|c|}
\hline Farmer A $\quad$ Farmer B & C: Cooperate & D: Defect \\
\hline C: Cooperate & Case1 $\left(\mathrm{R}_{\mathrm{A}}, \mathrm{R}_{\mathrm{B}}\right)$ & $\operatorname{Case} 2\left(\mathrm{~S}_{\mathrm{A}}, \mathrm{T}_{\mathrm{B}}\right)$ \\
\hline D: Defect & $\operatorname{Case} 3\left(\mathrm{~T}_{\mathrm{A}}, \mathrm{S}_{\mathrm{B}}\right)$ & Case4 $\left(\mathrm{P}_{\mathrm{A}}, \mathrm{P}_{\mathrm{B}}\right)$ \\
\hline
\end{tabular}

S: sucker, P: punishment, R: reward, T: temptation.

Table 2: $\quad$ Profit and loss index for the introduction of drip irrigation in C.

\begin{tabular}{|l|l|}
\hline Profit-and-Loss index & Each Farmer \\
\hline X1 initial cost & 12,000 Yuan/ha \\
\hline X2 Maintenance cost & X2 \\
\hline X3 time of work & X3 \\
\hline X4 decreasing water fee & $\begin{array}{l}\text { Only electric utility } \\
\text { expense }\end{array}$ \\
\hline $\begin{array}{l}\text { X5 Prospect for increasing } \\
\text { of production }\end{array}$ & $30 \%$ increase \\
\hline
\end{tabular}


The cooperation for drip irrigation is shown in ' $\mathrm{C}$ ', and no cooperation by cutting the tubes is shown in ' $\mathrm{D}$ '. The game plan initiated by each farmer and its resulting effects is shown by the profit and loss indices as follows:

(Case 1):

Each farmer takes the game plan ' $\mathrm{D}$ '.

$$
\text { Effect of farmers A and B: } P_{A}=P_{B}=-X_{1} \text {. }
$$

(Case 2):

Farmer A takes the game plan ' $\mathrm{C}$ ' and farmer B takes ' $\mathrm{D}$ '.

$$
\begin{gathered}
\operatorname{Benefit}(A)=S_{A}=-X_{1}-X_{2}-X_{3}+X_{4}, \\
\operatorname{Benefit}(B)=T_{B}=-X_{1}+X_{4} .
\end{gathered}
$$

In this case, each farmer paid the initial cost for the drip-irrigation facility. Farmer A decreased his profit since his yield was small and he was required to bear his portion of the cost. On the other hand, farmer B used groundwater more than farmer A through border irrigation and as a result, he gained a profit since the groundwater was cost-free.

(Case 3):

Farmer A initiates game plan ' $\mathrm{D}$ ' while farmer $\mathrm{B}$ initiates plan ' $\mathrm{C}$ ', which is opposite to the scenario in Case 2.

$$
\begin{gathered}
\operatorname{Benefit}(A)=T_{A}=-X_{1}+X_{4}, \\
\operatorname{Benefit}(B)=S_{B}=-X_{1}-X_{2}-X_{3}+X_{4} .
\end{gathered}
$$

(Case 4):

Each farmer cooperates with the drip-irrigation plan. In this case, both farmers can expect an obvious yield increase.

$$
\operatorname{Benefit}(\text { Aor B })=R=-X_{1}-X_{2}-X_{3}+X_{4}+X_{5} \text {. }
$$




\subsection{Considering the prisoner's dilemma}

Despite the incentive of no water fees and yield increases, farmers still sometimes refused to cooperate. In this case, collective facilities become involved in the so-called prisoner's dilemma and each farmer initiates game plan ' $\mathrm{D}$ ', as seen in Case 1.

Assuming that this situation is in fact the prisoner's dilemma, the following conditions are possible: Condition 1: $\mathrm{S}<\mathrm{P}<\mathrm{R}<\mathrm{T}$ and Condition 2: $2 \mathrm{R}>\mathrm{S}+\mathrm{T}$.

From Condition 1:

$$
\begin{gathered}
P_{A}-S_{A}=(a)-(b)=X_{2}+X_{3}-X_{4}>0 \Leftrightarrow X_{2}+X_{3}>X_{4}, \\
R_{A}-P_{A}=(f)-(a)=-X_{2}-X_{3}+X_{4}+{ }_{5}>0 \\
\Leftrightarrow X_{2}+X_{3}<X_{4}+X_{5}, \\
T_{A}-R_{A}=(d)-(f)=X_{2}+X_{3}-X_{5}>0 \Leftrightarrow X_{2}+X_{3}>X_{5} .
\end{gathered}
$$

From Condition 2:

$$
\begin{gathered}
2 R_{A}-S_{A}-T_{A}=(f)-(b)-(c)=2 X_{5}-X_{2}-X_{3}>0 \\
\Leftrightarrow X_{5}>\frac{1}{2}\left(X_{2}+X_{3}\right) .
\end{gathered}
$$

From eqns. (8) and (10), the cost of work and maintenance is lower compared to the profits from water-fee savings and yield increase for the installation of a dripirrigation system by collective facilities. In addition, the results of eqns. (6) and (9) indicate that the cost of work and maintenance is higher than such profits. It is assumed that this relationship between cost and profit allows farmers to select game plan ' $\mathrm{D}$ ' over ' $\mathrm{C}$ '. Therefore, to solve this problem, more than a double yield of water-fee reductions or advancement in maintenance techniques is required. However, the precondition of the partnership should be reinforced by feelings of trust, mutual confidence and mutual profit compared to only technical methods [4]. In this case, the government should support the edification of water-saving irrigation systems to initiate significant cooperation by the farmers.

\section{Conclusion}

This study examined the introduction of water-saving irrigation systems (drip irrigation) in the Trim River Basin, a particular arid region in China. It was suggested that yield increases occurred not only by advancing irrigation and cultivation management but also by restraining soil salinization and decreasing the groundwater level. Additionally, the cost of working and maintenance 
accrued by the introduction of the water-saving facilities was less compared with the incentives received in water-fee reductions and increased yields produced by the water-saving irrigation systems. Therefore, we suggest that either the current yield needs to be increased twofold or the water fee needs to be increased for effective management of water-saving irrigation facilities in collective management.

\section{Acknowledgments}

This research was supported by the Xayar County Government, the Xayar Water Resource Agency, Xinjiang University and the Xinjiang Uyghur Autonomous Region Water Resource Agency. Analysis was supported by graduate student Nozomu Kurihara who is currently employed with the Japan Broadcasting Corporation.

\section{References}

[1] Yamamoto T., Jalaldin A., Maimaidi A. \& Nagasawa T., The present condition and problem of agricultural water management in the northern part of the Taklamakan Desert. International Journal of Environment and Rural Development, pp. 50-55, 2010.

[2] Yamamoto T., Jalaldin A., Maimaidi A. \& Nagasawa T., Land reclamation and water management in an arid region: A case study of Xayar County in Xinjiang Uyghur autonomous region, China. Sustainable Irrigation Management, Technologies and Policies III, WIT Press, pp. 3-14, 2010.

[3] Kuhn, S., Prisoner's Dilemma. The Stanford Encyclopedia of Philosophy (Spring 2009 Edition), Edward N. Zalta (ed.), www.plato.stanford.edu /archives/spr2009/entries/prisoner-dilemma.

[4] Yamaoka K., Sato M., Horikawa N., Tomosho T., Ren Y. \& Tassnee O., Facilitating farmers' incentives and sustainability on participatory irrigation management by water users' group, Water Science, 49 (5), pp. 61-83, 2005. 